\title{
Use of Surgical Laser for Excision of a Neurofibroma Associated With Neurofibromatosis Type-1
}

\author{
Fabrício Rezende Amaral' ${ }^{1}$, Marcus Vinícius Lucas Ferreira ${ }^{2}$, Lucas Araújo Pereira Costa ${ }^{3}$, Patricia Alves \\ Drummond de Oliveira $^{4}$, Betânia Maria Soares ${ }^{5}$, Paulo Eduardo Alencar Souza ${ }^{6}$, Gerdal Roberto de Sousa ${ }^{7}$ \\ ${ }^{1}$ School of Dentistry, Centro Universitário Newton Paiva, Belo Horizonte, Minas Gerais, Brazil \\ ${ }^{2}$ Faculty of Dentistry, Universidade Federal de Minas Gerais, Minas Gerais, Belo Horizonte, MG, Brazil \\ ${ }^{3}$ School of Dentistry, Faculdade de Estudos Administrativos, FEAD, Belo Horizonte, Minas Gerais, Brazil \\ ${ }^{4}$ School of Dentistry, Faculdade de Estudos Administrativos, FEAD, Belo Horizonte, Minas Gerais, Brazil \\ ${ }^{5}$ Bioengineering Laboratory, Universidade Federal de Minas Gerais, Minas Gerais, Belo Horizonte, MG, Brazil and \\ Universidade de Itauna, Itauna, MG, Brazil \\ ${ }^{6}$ Department of Oral Pathology, School of Dentistry, Pontifical Catholic University of Minas Gerais, Belo Horizonte, MG, \\ Brazil \\ ${ }^{7}$ School of Dentistry, Centro Universitário Newton Paiva, Belo Horizonte, Minas Gerais, Brazil
}

\author{
*Correspondence to \\ Patricia Alves Drummond de \\ Oliveira, \\ Rua Padre Severino, 388 apt.12, \\ Belo Horizonte, MG, Brasil \\ Cep:30330-150 \\ Tel: 55-31-989392001 \\ Email: \\ patricia.a.drummond@gmail.com
}

Published online 28 July 2018

\begin{abstract}
Introduction: Neurofibromatosis type 1 (NF1) is an autosomal dominant genetic disorder that affects approximately $1 / 3500$ individuals. Various bone manifestations and peripheral nerves neoplastic lesions associated with NF1 are seen in the jaws. Several oral manifestations may occur in this disorder; therefore the dentist's knowledge and multidisciplinary management of these patients are extremely important.

Case Presentation: In the present article, we present the use of a high-power surgical laser to excise a neurofibroma in a patient with several intraoral manifestations associated with NF1. Conclusion: The use of diode laser $(808 \mathrm{~nm})$ for excision biopsy of tongue nodules showed no thermal damage to the tissue, allowing an adequate histopathological analysis of the neurofibroma
\end{abstract}

Keywords: Neurofibromatosis type 1; Neurofibroma; Von Recklinghausen disease, Diode laser.

\section{Introduction}

Neurofibromatosis (NF), an autosomal dominant genetic group of disorders that affects neural tissues, is divided in: NF type- 1 and NF type- $2 .{ }^{1}$ Neurofibromatosis type 1 (NF1), also known as Von Recklinghausen disease, affects approximately $1 / 3500$ individuals and accounts for $90 \%$ of all cases. ${ }^{2}$ The mutation occurs in a tumor suppressor gene located on the long arm of chromosome 17q11.2, which encodes the protein neurofibromin. ${ }^{3}$ About $50 \%$ of NF-1 affected patients have a positive family history of this disease with variable expressivity whereas the remaining patients represent a new mutation. ${ }^{4} \mathrm{NF}-1$ is characterized by multiple cutaneous neurofibromas, café au lait pigmentation on the skin, axillary or inguinal freckles, pigmented hamartomas of the iris, central nervous system tumors, and skeletal abnormalities. ${ }^{5}$ The patient with NF1 do not necessarily express all these alterations. The diagnostic criteria are met when the patient has two or more of these characteristics. ${ }^{6}$ The majority of the patients with NF1 present oral manifestations. ${ }^{7}$ The main oral manifestations in NF-1 include oral soft tissues neurofibromas, preferably located on the tongue, hypoplasia of the mandibular ramus with radiolucency in the sigmoid notch, hypoplasia of the temporal, and mandibular components of the temporomandibular joint, absence of sphenoid bone, enlarged alveolar process with dental spacing, enlargement of inferior alveolar canal and mandibular foramen, changes in coronoid notch morphology, and decreased mandibular angle. ${ }^{8}$ The neurofibromas associated with NF1 are mostly benign, but malignant transformation may occur, especially the plexiform variant. ${ }^{9}$

Diode lasers can be used to perform oral soft tissue procedures such as frenectomy, gingival recontouring, crown lengthening, implant exposure and other minor surgeries related to daily clinical treatments. These lasers can also be used in oral pathology to excise oral lesions, such as: fibroma, mucocele, hyperkeratosis, Fordyce granules, neurofibromas and other types of soft tissue lesions. ${ }^{10}$ Some of the advantages of using a laser to excise soft lesions may be listed as: excellent hemostasis, reduced swelling and post-operative discomfort, minimal 
or no suturing, sterilization of the surgical area, patient acceptance and satisfaction. ${ }^{11}$ The specimens obtained with a diode laser have good readability. ${ }^{12}$ We present the use of diode surgical laser emitting in $808 \mathrm{~nm}$ to excise a neurofibroma located on the tongue of a patient with intraoral manifestations of NF1, who did not know about her condition.

\section{Case Presentation}

A 44-year-old female, sought dental care at FEAD dental school. During anamnesis, the patient proved to be very confused about reporting her complaint and its systemic condition. During anamnesis, she reported no use drugs and no systemic diseases. The clinical examination showed small nodules scattered throughout the face (Figure 1A). The patient reported having similar nodules located on the abdomen and the presence of some spots on the body. There was no relevant family history of similar nodules and spots. Intra-oral examination revealed two nodules with a firm consistence and coloration similar to mucosa located on the dorsal surface of the tongue (Figure 1B). Alveolar bone expansion, separation of anterior teeth, and overgrowth of attached gingiva without inflammation were observed (Figure 2A). An increase in the diameter of the mental foramen and width of the mandibular canal was noted in the panoramic radiograph. Furthermore, we observed an increase in lateral bowing of mandibular ramus, change in the coronoid notch and mandibular angle reduction (Figure 2B). During the extraction of residual tooth roots, we noted the presence of dysplastic bone. An excisional biopsy was performed on one of the tongue nodules by using a high-power laser (Figure 3), and microscopic examination confirmed the presence of neurofibroma. The laser, a $9 \mathrm{~W}$ diode laser (gallium arsenide, Thera Laser Surgery, DMC, São Carlos, Brazil) was used with the following parameters: wavelength emission at $808 \mathrm{~nm} \pm 10 \mathrm{~nm}$ in pulsed wave mode, $1.5 \mathrm{~W}$ output, pulse width of 25 milliseconds, pulse interval of $30 \mathrm{~ms}$, repetition rate of $33.3 \mathrm{~Hz}$, average power of $1.25 \mathrm{~W}$ and a fiber optic delivery system of $400 \mu \mathrm{m}$ in diameter. The $808 \mathrm{~nm}$ diode laser showed to be effective to perform this kind of surgery with minimal bleeding, therefore, sutures were not necessary. It has been demonstrated that
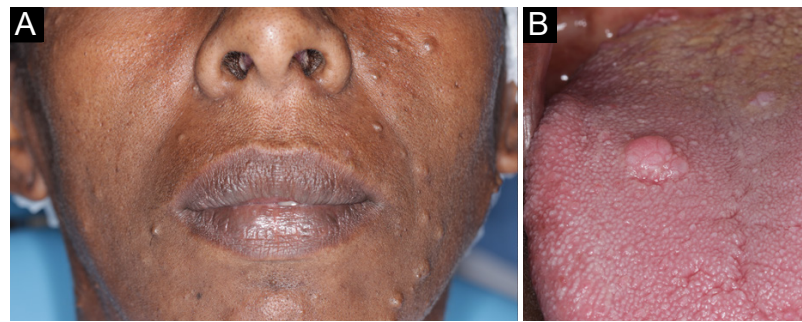

Figure 1. (A) Extraoral View Showing Small Nodules Scattered Throughout the Face. (B) Intraoral view showing two nodules on the surface of the tongue. diode laser surgery is less invasive compared with scalpel conventional surgery, and patient presents good healing aspects without the need for analgesic medication. The HE stained (Figure 4) specimens showed a connective tissue with fusiform cell proliferation. These cells had basophilic and wavy nuclei and scant cytoplasm permeated by collagen fibers and nerve bundles. Based on these findings, the diagnosis of Neurofibroma was given. The patient was referred to a referral center for patients with NF1 for evaluation, diagnosis and monitoring.

\section{Discussion}

NF-1 is a disease that affects 1 in 3500 individuals and is still little known to dentists, despite several oral manifestations that may be associated with it. This condition is due to changes in the NF1 gene located on the long arm of chromosome $17 .{ }^{3}$ Definitive diagnosis of this condition is of the utmost importance, because of the possibility of malignant transformation of neurofibromas. Malignant peripheral nerve sheath tumor (MPNST) is the main malignancy that occurs in patients with NF1. ${ }^{13}$ In the case reported here, the patient had difficulties with communication during anamnesis and was not aware of her condition. A characteristic of NF-1 is the possibility of the patient having neurocognitive deficits. ${ }^{14}$ According to the literature, if the patient has two or more possible features associated with this condition, the diagnosis is NF1. ${ }^{7}$ In the present case, the patient had multiple cutaneous nodules, café au lait pigmentation on the skin, neurofibromas in the tongue, and several alterations were found in the gnathic bones, such as an increase in diameter of the mental foramen and in width of the mandibular

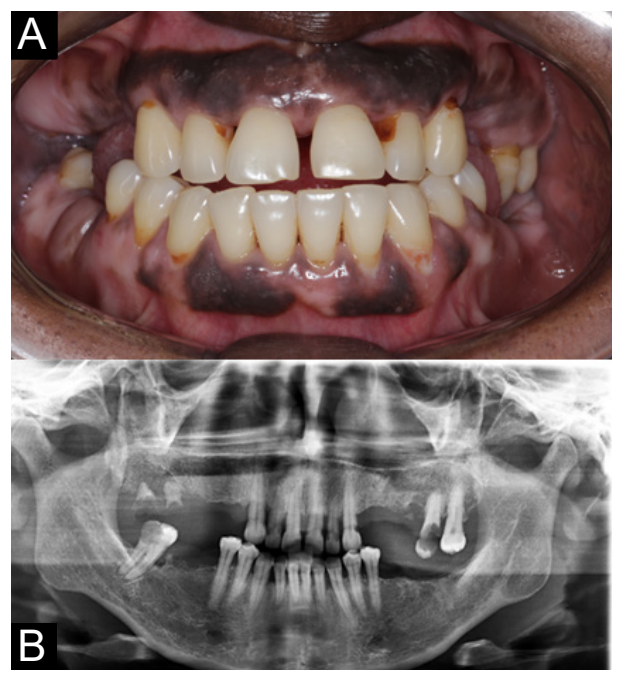

Figure 2. (A) Intraoral view showing expansion of the alveolar bone, separation of anterior teeth, overgrowth of attached gingiva, and general pigmentation. (B) View of panoramic radiograph showing increase in diameter of the mental foramen, width of the mandibular canal, increase in lateral bowing of mandibular ramus, change in the coronoid notch and reduction in the mandibular angle. 


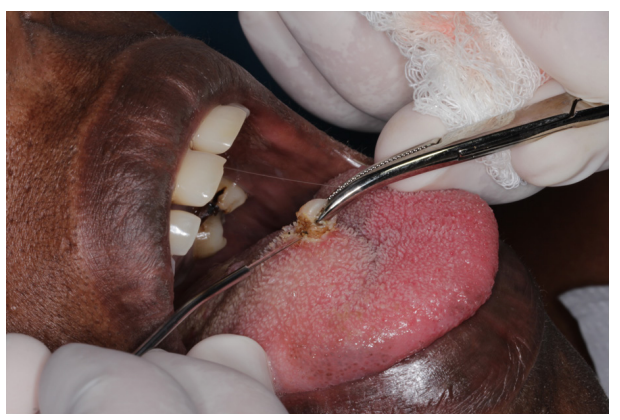

Figure 3. Excisional Biopsy of One of the Tongue Nodules by Using a High Power Laser.

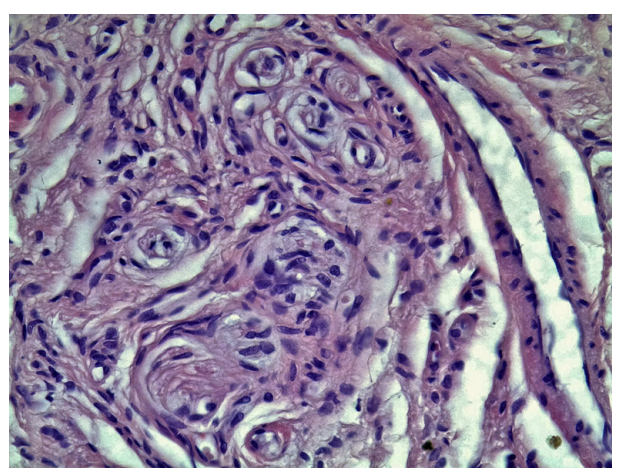

Figure 4. Histological aspect of the lesion showing fibrous connective tissues with fusiform cells proliferation presenting basophilic and wavy nuclei and scant cytoplasm permeated by collagen fibers and nerve bundles (hematoxylin and eosin; x400 magnification).

canal, as well as an increase in lateral bowing of the mandibular ramus, change in the coronoid notch, and decrease in the mandibular angle. Bone alterations are not reported in all patients with NF1. This may be supported by genetic mechanisms such as NF1 gene haploinsufficiency that increases osteoclast activity in affected individuals. ${ }^{15}$ Gingival enlargement and pigmentation are common manifestations present in patients with NF1. ${ }^{16}$ In the case reported here, the patient showed an overgrowth of attached gingiva and general pigmentation. Given these present manifestations associated with NF1, the patient was referred to a specialized center for diagnosis, treatment and monitoring of NF1. It is very important for these patients to have multidisciplinary management because of the increased risk of endocrine disorders and malignant transformation. These patients should receive genetic counseling to prevent vertical transmission. Lasers can cause thermal damage to tissues, but the use of appropriate settings, such as power output, type of optic fiber used, emission modalities, wavelength, may diminish or even eliminate these effects on the target and surrounding tissues. ${ }^{17}$ Some attention must be given to emission modalities, continuous wave (CW) or pulsed emission. Clinicians should always prefer the pulsed emission because it allows the remaining tissue to cool before the next pulse of laser energy.10 This mechanism prevents tissue overheating. The thermal effect on tissues must be minimized to enable the therapeutic effect to be obtained with the lowest irradiation time possible. ${ }^{18}$ In 2007 D'Arcangelo et $\mathrm{al}^{19}$ compared the use of a diode laser $(808 \mathrm{~nm})$ with that of a scalpel, and showed that due to tissue thermal damage, the continuous mode diode laser tended to produce more pronounced changes than the conventional surgical procedure. The use of diode laser $(808 \mathrm{~nm})$, with $1.5 \mathrm{~W}$ output power in a pulsed wave mode, with pulse width of 25 milliseconds, pulse interval of 30 milliseconds, and a $400 \mu \mathrm{m}$ fiber optic delivery system showed optimal results for excising a neurofibroma associated with NF1, showing no thermal damage, and protecting the tissue for an adequate histopathological analysis.

\section{Ethical Considerations}

The patient signed a written informed consent prior to beginning the treatment.

\section{Conflict of Interests}

The authors declare no conflict of interest.

\section{References}

1. Karajannis MA, Ferner RE. Neurofibromatosis-related tumors: emerging biology and therapies. Curr Opin Pediatr. 2015;27(1):26-33. doi:10.1097/mop.0000000000000169

2. Gerber PA, Antal AS, Neumann NJ, et al. Neurofibromatosis. EurJMed Res. 2009;14(3):102-105.

3. AbramowiczA, GosM.Neurofibromin in neurofibromatosis type 1 - mutations in NF1gene as a cause of disease. Dev Period Med. 2014;18(3):297-306.

4. Rasmussen SA, Friedman JM. NF1 gene and neurofibromatosis 1. Am J Epidemiol. 2000;151(1):33-40.

5. Kresak JL, Walsh M. Neurofibromatosis: A Review of NF1, NF2, and Schwannomatosis. J Pediatr Genet. 2016;5(2):98104. doi:10.1055/s-0036-1579766

6. Gutmann DH, Aylsworth A, Carey JC, et al. The diagnostic evaluation and multidisciplinary management of neurofibromatosis 1 and neurofibromatosis 2. JAMA. 1997;278(1):51-57.

7. Shapiro SD, Abramovitch K, Van Dis ML, et al. Neurofibromatosis: oral and radiographic manifestations. Oral Surg Oral Med Oral Pathol. 1984;58(4):493-498.

8. Javed F, Ramalingam S, Ahmed HB, et al. Oral manifestations in patients with neurofibromatosis type-1: a comprehensive literature review. Crit Rev Oncol Hematol. 2014;91(2):123-129. doi:10.1016/j.critrevonc.2014.02.007

9. Ingham S, Huson SM, Moran A, Wylie J, Leahy M, Evans DG. Malignant peripheral nerve sheath tumours in NF1: improved survival in women and in recent years. Eur J Cancer. 2011;47(18):2723-2728. doi:10.1016/j. ejca.2011.05.031

10. Aldelaimi TN, Khalil AA. Clinical Application of Diode Laser $(980 \mathrm{~nm})$ in Maxillofacial Surgical Procedures. J Craniofac Surg. 2015;26(4):1220-1223. doi:10.1097/ scs.0000000000001727

11. Azma E, Safavi N. Diode laser application in soft tissue oral surgery. J Lasers Med Sci. 2013;4(4):206-211. 
12. Capodiferro S, Maiorano E, Loiudice AM, Scarpelli F, Favia G. Oral laser surgical pathology: a preliminary study on the clinical advantages of diode laser and on the histopathological features of specimens evaluated by conventional and confocal laser scanning microscopy. Minerva Stomatol. 2008;57(1-2):1-6.

13. Janardhanan $M$, Rakesh S, Vinod Kumar R. Intraoral presentation of multiple malignant peripheral nerve sheath tumors associated with neurofibromatosis-1. J Oral Maxillofac Pathol. 2011;15(1):46-51. doi:10.4103/0973029x.80025

14. Lehtonen A, Howie E, Trump D, Huson SM. Behaviour in children with neurofibromatosis type 1: cognition, executive function, attention, emotion, and social competence. Dev Med Child Neurol. 2013;55(2):111-125. doi:10.1111/j.1469-8749.2012.04399.x

15. Stevenson DA, Yan J, He Y, et al. Multiple increased osteoclast functions in individuals with neurofibromatosis type 1. Am J Med Genet A. 2011;155a(5):1050-1059. doi:10.1002/ajmg.a.33965

16. Mahajan A, Dixit J, Bhardwaj A. Gingival enlargement in neurofibromatosis type 1: a case report and literature review. J Contemp Dent Pract. 2010;11(2):057-063.

17. Goharkhay K, Moritz A, Wilder-Smith P, et al. Effects on oral soft tissue produced by a diode laser in vitro. Lasers Surg Med. 1999;25(5):401-406.

18. Cercadillo-Ibarguren I, Espana-Tost A, ArnabatDominguez J, Valmaseda-Castellon E, Berini-Aytes L, Gay-Escoda C. Histologic evaluation of thermal damage produced on soft tissues by CO2, Er,Cr:YSGG and diode lasers. Med Oral Patol Oral Cir Bucal. 2010;15(6):e912-918.

19. D’Arcangelo C, Di Nardo Di Maio F, Prosperi GD, Conte E, Baldi M, Caputi S. A preliminary study of healing of diode laser versus scalpel incisions in rat oral tissue: a comparison of clinical, histological, and immunohistochemical results. Oral Surg Oral Med Oral Pathol Oral Radiol Endod. 2007;103(6):764-773. doi:10.1016/j.tripleo.2006.08.002 